\title{
KEEFEKTIFAN MODEL SOMATIC, AUDITORY, VISUALIZATION, INTELLECTUALLY (SAVI) TERHADAP HASIL BELAJAR SBDP KARYA ORIGAMI KELAS III SD GUGUS RUJAKBELING KECAMATAN KEBUMEN.
}

\author{
Irma Kumala Sari ${ }^{1}$, Rokhmaniyah ${ }^{2}$, Tri Saptuti $\mathbf{S}^{3}$ \\ Universitas Sebelas Maret \\ irmakumala65@gmail.com
}

Article History

accepted 01/10/2020

approved 01/11/2020

published 01/12/2020

\begin{abstract}
The Somatic Auditory Visualization Intellectually (SAVI) model is one of innovative learning models. It needs to accomplish learning purposes. The study aimed to examine the effectiveness of SAVI model on third grade origami project learning outcomes. The research was a quasi-experimental research in the form of Nonequivalent Control Group Design. The population was all third grade students of elementary schools in Rujakbeling cluster, Kebumen sub-district in academic year of 2019/2020. The sampling technique used cluster random sampling. Data collection techniques used test. Data analysis techniques used t-test. The results show that the Sig. value in the $t$-test is 0.000 , which means that the Sig. value $<0.05$, it can be concluded that $\mathrm{Ha}$ in this research is accepted. It concludes that the Somatic Auditory Visualization Intellectually (SAVI) model is more effective in improving third grade origami project learning outcomes of elementary schools in Rujakbeling cluster, Kebumen sub-district. Keywords: effectiveness, Somatic Auditory Visualization Intellectually (SAVI), learning outcomes, origami project
\end{abstract}

\begin{abstract}
Abstrak
Model pembelajaran yang inovatif sangat dibutuhkan untuk tercapainya tujuan pembelajaran, salah satunya model pembelajaran Somatic Auditory Visualization Intellectually (SAVI). Tujuan penelitian ini menguji keefektifan model Somatic Auditory Visualization Intellectually (SAVI) terhadap hasil belajar SBdP Karya Origami Kelas III SD. Penelitian ini merupakan penelitian eksperimen semu (quasi eksperimental) dengan bentuk Nonequivalent Control Group Design. Populasi penelitian ini adalah seleruh siswa kelas III SD Gugus Rujakbeling Kecamatan Kebumen tahun ajaran 2019/2020. Sampel penelitian ini dipilih menggunakan teknik cluster random sampling. Teknik pengumpulan data dalam penelitian menggunakan metode tes. Teknik analisis data dalam penelitian ini menggunakan uji $t$-tes. Hasil penelitian menunjukkan nilai Sig uji $t$-test $0,000<0,05$, yang berarti hipotesis $\mathrm{H}_{1}$ dalam penelitian ini diterima yaitu model SAVI lebih efektif terhadap hasil belajar SBdP karya origami, Berdasarkan hasil penelitian tersebut dapat disimpulkan bahwa model Somatic Auditory Visualization Intellectually (SAVI) lebih efektif terhadap hasil belajar SBdP Karya Origami Kelas III SD Gugus Rujakbeling Kecamatan Kebumen.
\end{abstract}

Kata kunci: efektivitas, SAVI, hasil belajar, SBdP 


\section{PENDAHULUAN}

Kualitas sumber daya manusia (SDM) sangatlah penting untuk kemajuan suatu negara. Oleh sebab itu, maka pemerintah dengan gencar meningkatkan kualitas SDM agar mampu bersaing di pasar global dengan cara meningkatkan sistem pendidikan Indonesia agar mampu mencetak SDM yang unggul dan siap bersaing di pasar global.

Pendidikan merupakan cara yang dilakukan seseorang secara sadar untuk menumbuhkan sifat kepribadian ataupun potensi yang dimilikinya baik itu dari segi intelektual, fisik, emosional, dan sosial yaitu melewati kegiatan proses belajar mengajar baik di sekolah ataupun di luar sekolah seperti yang tercantum pada pasal 1 dalam UU Nomor 20 Tahun 2003 tentang Sistem Pendidikan Nasional (SISDIKNAS, 2003: 3)

Untuk mewujudkan pendidikan yang berkualitas tinggi maka SISDIKNAS menetapkan pedoman penyelenggaraan pendidikan yang disebut dengan kurikulum. Kurikulum yang dianut negara Indonesia saat ini yaitu kurikulum 2013 yang bertujuan untuk menciptakan siswa yang beriman, produktif, kreatif, inovatif, dan berkarakter. Pada kurikulum 2013 terdapat pengintergrasian mata pelajaran menjadi satu kesatuan yang padu. Salah satunya muatan pelajaran (mupel) SBdP yang ikut diintergrasian menjadi satu kesatuan dengan mata pelajaran lain.

SBdP merupakan pendidikan seni yang berpedoman dengan nilai budaya dari suatu daerah yang terangkum dalam bebrapa aspek yaitu seni rupa, seni musik dan seni tari (Susanto, 2016). Oleh sebab itu, SBdP penting diajarkan kepada siswa karena mupel ini melatih keterampilan siswa agar mampu berkembang dengan baik. Mupel ini tidak hanya fokus dengan aspek kogitif anak melainkan mupel ini juga terfokus dengan aspek psikomotor yang dimiliki siswa. SBdP ditingkat pendidikan dasar bertujuan untuk meningkatkan kemampuan siswa dalam mengembangkan seni dari berbagai aspek baik secara pengetahuan ataupun keterampilannya. seperti yang tercantum dalam Permendikbud No. 57 Tahun 2014. Tercapainya tujuan pembelajaran apabila dalam proses pembelajaran, pendidik dapat menyampaikan serta memperaktikan materi dengan sungguh-sungguh. Pada proses pembelajaran, pendidik juga harus mempunyai trik ataupun cara agar siswa tertarik pada proses/pembelajaran sehingga siswa dapat berperan aktiflsaat pembelajaran berlangsung.

Namun dalam pelaksanaan pembelajaran SBdP masih menjumpai permasalahan baik dari segi proses pembelajaran, pendidik ataupun dari peserta didik. Hal ini dijumpai di SD Gugus Rujakbeling Kecamatan Kebumen Kabupaten Kebumen. Berdasarkan hasil observasi dan wawancara, pembelajaran SBdP di Gugus Rujakbeling masih kurang optimal yang menyebabkan hasil belajar juga masih kurang optimal. Proses pembelajarannya masih berpusat kepada guru dan belum menggunakan model pembelajaran yang inovatif. Sesuai dengan tahap perkembangan kognitif siswa, siswa kelas III menduduki tahap operasional kongkrit sehingga pada proses pembelajaran diperlukan benda kongkrit dan arahan dari guru dalam proses pembelajaran. Akan tetapi, siswa belum mendapatkan contoh nyata dalam proses pembelajaran dan guru masih menggunakan metode penugasan dalam pembuatan suatu karya sehingga mengurangi minat siswa dalam mengikuti pembelajaran.

Permasalahan yang terjadi pada SD Gugus Rujakbeling Kecamatan Kebumen yaitu proses pembelajaran belum menggunakan model yang inovatif yang menyebabkan hasil belajar siswa kelas III semester 2 tahun ajaran 2018/2019 SD segugus Rujakbeling pada muatan pelajaran SBdP menunjukkan dari 125 siswa terdapat 50 siswa atau $40 \%$ yang belum mencapai Kriteria Ketuntasan Minimal (KKM).

Oleh sebab itu, diperlukan pembenahan proses pembelajaran SBdP terutama mengenai model pembelajaran yang dipergunakan dalam pembelajaran Kompetensi Dasar (KD) teknik potong, lipat, dan sambung. KD ini dapat diterapkan pada pembelajaran origami. Origami merupakan suatu proses menghasilkan karya dengan melibatkan kelenturan tangan untuk menghasilkan aneka bentuk (Mulyanti, 2014). 
Kegiatan origami dapat diterapkan pada KD 3.4 dilakukan dengan cara memotong, melipat dan menyambung kertas agar menjadi suatu objek yang ornamental.

Pada KD ini, peneliti mengajukan solusi alternatif agar pembelajaran di SD Gugus Rujakbeling dapat berjalan dengan maksimal. Solusi itu adalah menerapkan model pembelajaran Somatic, Auditori, Visual, Intelektual (SAVI) diharapkan dapat mengatasi permasalahan pembelajaran SBdP. Model SAVI merupakan salah satu model yang mampu melibatkan semua anggota tubuh baik alat indra, alat gerak, ataupun kemampuan otak dalam melakukan proses belajar mengajar (Huda, 2017). Model SAVI harus melibatkan semua alat indra yang dimiliki siswa dalam proses pembelajaran seperti mata, tangan, pikiran dan lain-lain (Shoimin,2017). Oleh karena itu, model SAVI cocok sesuai dengan pembelajaran KD 3.4 dan KD 4.4 teknik potong, lipat, dan sambung pada SBdP karena dalam proses pembelajaran menuntut untuk melibatkan semua alat indra yang dimiliki siswa.

Berdasarkan uraian latar belakang tersebut, pada tahun ajaran 2019/2020 peneliti berkolaborasi dengan guru kelas untuk melakukan penelitian kuantitatif dengan metode eksperimen yang berjudul "Keefektifan Model Somatic, Auditory, Visualization, Intellectually (SAVI) terhadap Hasil Belajar SBDP Karya Origami Kelas III SD Gugus Rujakbeling Kecamatani Kebumen". Sehingga tujusn penelitian ini yaitu untuk menguji keefektifan model Somatic Auditory Visualization Intellectually (SAVI) terhadap hasil belajar SBdP Karya Origami Kelas III.

\section{METODE}

Penelitian ini merupakan penelitian kuantitatif dengan metode eksperimen semu (quasi eksperimental) dengan bentuk Nonequivalent Control Group Design (Sugiyono, 2015). Populasi penelitian ini adalah seluruh siswa kelas III SD Gugus Rujakbeling Kecamatan Kebumen tahun ajaran 2019/2020. Sampel penelitian dipilih menggunakan metode cluster random sampling. Sampel penelitian ini meliputi SDN 1 Kebumen dan SDN 2 Kebumen sebagai kelas eksperimen, serta SDN 7 Kebumen dan SD Kristen Penabur sebagai kelas kontrol. Penelitian ini dilaksanakan bulan Maret 2020 di empat sekolah yang berada di Kecamatan Kebumen, Provinsi Jawa Tengah. Teknik pengumpulan data pada peneitian ini menggunakan metode tes yang terdiri dari tes tertulis dan tes unjuk kerja. Tes tertulis untuk mengukur kemampuan siswa pada aspek kognitif sementara tes unjuk kerja untuk mengukur kemampuan siswa pada aspek psikomotor. Peneliitian diawali dengan melakukan pretest dan diakhiri dengan posttest. Pembelajaran dilakukan sebanyak dua kali pertemuan. Sebelum dilakukan penelitian, instrument penelitian diujicobakan terlebih dahulu agar instrument valid. Kemudian hasil penelitian dianalisis menggunakan uji $t$-test yang dilakukan dengan bantuan aplikasi PASW Statistics 23.

\section{HASIL DAN PEMBAHASAN}

Pada penelitian ini diperoleh data nilai kognitif dan psikomotor. Analisis data akhir penelitian ini menggunakan uji $t$-test. Uji $t$-test yang digunakan dalam mengolah data penelitian ini terdiri dari dua yaitu uji paired sample t-test dan uji idependent sample t-test.

Data yang digunakan untuk melakukan uji paired sample t-test yaitu hasil belajar SBdP aspek kognitif yang berasal dari nilai pretest dan posttest pada masingmasing kelas yaitu kelas eksperimen dan kelas kontrol. Untuk uji paired sample $t$-test dapat dilihat pada tabel 1 . 
Tabel 1. Output uji paired sample t-test

Paired Samples Test

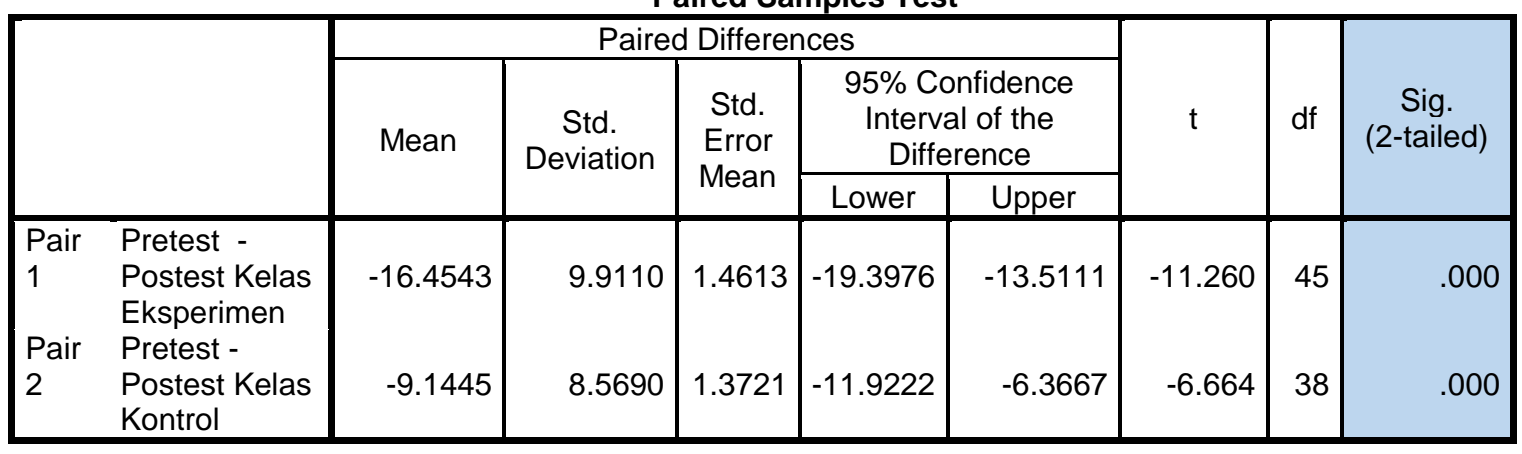

Berdasarkan tabel 1, merupakan output yang menjelaskan tentang hasil uji sampel berpasangan (paired sample t-test) pada hasil belajar SBdP aspek kognitif. Berdasarkan tabel di atas dapat disimpulkan bahwa:

1) Berdasarkan output Pair 1 diperoleh nilai Sig. (2 tailed) sebesar 0.000 yang artinya nilai Sig. < $0.05(5 \%)$, maka dapat disimpulkan ada perbedaan rata-rata hasil belajar siswa untuk nilai pretest kelas eksperimen dengan nilai posttest kelas eksperimen.

2) Berdasarkan output Pair 2 diperoleh nilai Sig.(2 tailed) sebesar 0.000 yang artinya nilai Sig. < $0.05(5 \%)$, maka dapat disimpulkan ada perbedaan rata-rata hasil belajar siswa untuk nilai pretest kelas kontrol dengan nilai posttest kelas kontrol.

Dari analisis di atas, keduanya sama-sama terdapat perbedaan rata-rata hasil belajar siswa untuk nilai pretest dengan nilai posttest baik pada kelas eksperimen dan kelas kontrol. Namun, apabila dilihat dari nilai selisih rata-rata pretest dan posttest maka terdapat perbedaan nilai. Selisih rata-rata pretest dan posttest pada kelas eksperimen dengan model pembelajaran SAVI sebesar 16.454. Sedangkan nilai selisih rata-rata pretest dan posttest pada kelas kontrol sebesar 9.144. Karena selisih ratarata pretest dan posttest pada kelas eksperimen lebih besar dibandingkan kelas kontrol, maka Ha diterima yang berarti bahwa pembelajaran menggunakan model SAVI lebih efektif terhadap hasil belajar SBdP Karya Origami.

Sementara pada uji idependent sample t-test, data yang digunakan adalah nilai aspek psikomotor yang diperoleh dari tes unjuk kerja. Untuk uji paired sample t-test dapat dilihat pada tabel 2.

Tabel 2. Output uji idependent sample t-test

\begin{tabular}{|c|c|c|c|c|c|c|c|c|c|c|}
\hline & & $\begin{array}{l}\text { Leve } \\
\text { Tes } \\
\text { Equa } \\
\text { Varia }\end{array}$ & $\begin{array}{l}\text { ne's } \\
\text { for } \\
\text { ity of } \\
\text { nces }\end{array}$ & \multicolumn{7}{|c|}{ t-test for Equality of Means } \\
\hline & & & & & & Sig. & Mean & Std. Error & $\begin{array}{r}95 \% \text { Co } \\
\text { Interva } \\
\text { Diffe }\end{array}$ & $\begin{array}{l}\text { afidence } \\
\text { of the } \\
\text { ence }\end{array}$ \\
\hline & & $\mathrm{F}$ & Sig. & $\mathrm{t}$ & df & (2-tailed) & Difference & Difference & Lower & Upper \\
\hline $\begin{array}{l}\text { Nilai } \\
\text { Keterampila } \\
\text { n Karya } \\
\text { Teknik } \\
\text { Potong } \\
\text { Lipat dan } \\
\text { Sambung }\end{array}$ & $\begin{array}{l}\text { Equal } \\
\text { variances } \\
\text { assumed } \\
\text { Equal } \\
\text { variances } \\
\text { not } \\
\text { assumed }\end{array}$ & .008 & .930 & $\begin{array}{l}4.230 \\
4.227\end{array}$ & $\begin{array}{r}83 \\
\\
80.4 \\
89\end{array}$ & .000 & 7.3682 & $\begin{array}{l}1.7420 \\
1.7433\end{array}$ & $\begin{array}{l}3.9035 \\
3.8992\end{array}$ & $\begin{array}{l}10.8328 \\
10.8372\end{array}$ \\
\hline
\end{tabular}

Berdasarkan hasil output tabel 2. diperoleh nilai Sig(2 tailed) sebesar 0.000, yang artinya terdapat perbedaan hasil belajar SBdP Karya Origami antara kelas eksperimen dengan kelas kontrol. Namun, jika dilihat dari rata-rata nilai tes unjuk kerja, 
kelas eksperimen mimiliki nilai rata-rata lebih besar dibandingkan kelas kontrol yaitu $84,063>76,695$. Hal ini membuktikan bahwa model SAVI lebih efektif terhadap hasil belajar SBdP karya origami yang artinya $\mathrm{H}_{1}$ diterima dan Ho ditolak.

Dari analisis di atas, hasil belajar SBdP Karya Origami baik dari aspek kognitif maupun psikomotor antara kelas eksperimen dengan kelas kontrol terdapat perbedaan rata-rata hasil belajar. Maka dapat disimpilkan $\mathrm{H}_{1}$ diterima yang artinya model SAVI lebih efektif terhadap hasil belajar SBdP karya origami kelas III SD Gugus Rujakbeling Kecamatan Kebumen.

Efektivitas model pembelajaran SAVI terhadap hasil belajar SBdP siswa kelas III SD dikarenakan model SAVI memiliki langkah atau tahapan pembelajaran yang didesain untuk menyampaikan pengetahuan dan keterampilan serta melibatkan panca indra yang dimiliki siswa serta menghadirkan benda kongkrit dalam pembelajaran. Hal itu sesuai dengan tahapan perkembangan siswa kelas III yang sedang berada pada tahapan operasional kongkrit (Trianto, 2007). Oleh sebab itu, membuat siswa secara aktif ikut serta dalam proses pembelajaran. Hal ini sesuai dengan pendapat Suyanto Jihad (2016:81) bahwa model SAVI dalam proses belajar yang banyak melibatkan panca indra akan semakin baik hasil belajar yang bisa dicapai. Sebaliknya, pola pembelajaran yang cenderung membuat siswa tidak aktif secara fisik dalam jangka waktu lama akan menyebabkan kejenuhan otak, belajar menjadi lambat, bahkan kemampuan belajar dapat terhenti, dengan kata lain hilangnya semangat belajar pada diri siswa. Model SAVI memiliki keunggulan pada langkah-langkah pembembelajaran di kelas yang terdiri dari Somatic yang artinya learning by doing, Auditory yang artinya learning by talking and hearing, Visualization yang artinya learning by observing and picturing, dan langkah terakhir Intellectually yang artinya learning by problem solving and thinking (Shoimin: 2017). Dalam penelitian ini guru berperan sebagai fasilitator dan motivator untuk membimbing serta mengarahkan siswa agar terciptanya proses belajar yang baik dan sesuai dengan tahapan SAVI.

\section{SIMPULAN}

Berdasarkan hasil penelitian yang diperoleh, maka dapat disimpulkan bahwa model Somatic Auditory Visualization Intellectually (SAVI) lebih efektif terhadap hasil belajar SBdP karya origami kelas III SD Gugus Rujakbeling Kecamatan Kebumen. Hal itu terbukti berdasarkan uji $t$-test diperoleh nilai Sig. sebesar 0.000 yang artinya nilai Sig. < 0.05, maka disimpulkan bahwa $\mathrm{H}_{1}$ dalam penelitian ini diterima yaitu model Somatic Auditory Visualization Intellectually (SAVI) lebih efektif terhadap hasil belajar SBdP karya origami kelas III SD Gugus Rujakbeling Kecamatan Kebumen

Berkaitan dengan hasil penelitian yang diperoleh, penulis memberikan saran sebagai berikut: (1) bagi siswa, siswa diharapkan dapat berpartisipasi secara aktif dalam psorses pembelajaran dan siswa mampu meningkatkan kemampuan psikomotor yang dimiliki; (2) bagi guru, hendaknya guru dapat menggunakan model pembelajaran yang inovatif supaya siswa tidak merasa bosan dan tidak merasa kesulitan dalam memahami materi pembelajaran seperti menerapkan model SAVI dan perlu mempraktikan materi yang diajarkan agar siswa mendapatkan pengalamannya sendiri dalam proses pembelajaran sehingga mencapai hasil yang optimal; (3) bagi sekolah, penggunaan model SAVI diharapkan memberikan refrensi bagi guru-guru di SD Gugus Rujakbeling Kecamatan Kebumen, Kabupaten Kebumen untuk mengembangkan model yang inovatif dan menyenangkan sehingga kualitas pembelajaran menjadi lebih baik dan hasil yang optimal; (4) bagi peneliti selanjutnya, hasil penelitian ini disarankan agar digunakan secara bijak dalam penelitian mendatang. 


\section{DAFTAR PUSTAKA}

Huda, M. 2017. Model-Model Pegajaran dan Pembelajaran. Yogyakarta: Pustaka Pelajar.

Mulyanti, A. 2014. Peningkatan Keterampilan Motorik Halus Melalui Origami Pada Anak Kelompok A TK Kusuma Baciro Gondokusuman Yogyakarta. SKRIPSI. Diperoleh pada 12 Desember 2019, dari http://eprints.uny.ac.id/13016/1/SKRIPSI_ATIK\%20MULYATI_NIM.121112 47007.pdf

Peraturan Menteri Pendidikan dan Kebudayaan Nomor 57 Tahun 2014 tentang Kurikulum 2013 Sekolah Dasar/Madrasah Ibtidayah, Jakarta: Sekertariat Negara

Shoimin, A. 2014. 68 Model Pembelajaran Inovatif dalam Kurikulum 2013. Yogyakarta: AR-Ruzz Media.

Sugiyono. 2015. Metode Penelitian Pendidikan. Bandung: Penerbit Alfabeta.

Susanto, A. 2014. Teori Belajar \& Pembelajaran di Sekolah Dasar. Jakarta: Prenadamedia Group.

Suyanto dan Jihad. 2013. Menjadi Guru Profesional Strategi meningkatkan kualifikasi dan kualitas Guru di Era Global. Jakarta:Erlangga.

Trianto. 2007. Model Pembelajaran Terpadu dalam Teori dan Praktek. Jakarta: Prestasi Pustaka

Undang-Undang Nomor 20 tahun 2003 tentang Sistem Pendidikan Nasional, Jakarta: Sekretariat Negara. 